\title{
X-ray dynamic observation of cervical degenerative disease induced by unbalanced dynamic and static forces in rats ${ }^{1}$
}

\author{
Hua Xie', Yongjing Huang", Luming Nong 'I", Nanwei Xu'v, Gongming Gaov, Dong Zhouv
}

'PhD, Department of Orthopedics, Jintan People's Hospital, Jiangsu, P.R. China. Manuscript preparation and writing. "PhD, Department of Orthopedics, Changzhou Second People's Hospital Affiliated to Nanjing Medical University, Jiangsu, P.R. China. Manuscript preparation and writing.

I'PhD, Department of Orthopedics, Changzhou Second People's Hospital Affiliated to Nanjing Medical University, Jiangsu, P.R. China. Critical revision, final approval.

IVPhD, Department of Orthopedics, Changzhou Second People's Hospital Affiliated to Nanjing Medical University, Jiangsu, P.R. China. Analysis and interpretation of data, statistical analysis.

'PhD, Department of Orthopedics, Changzhou Second People's Hospital Affiliated to Nanjing Medical University, Jiangsu, P.R. China. Technical procedures.

\begin{abstract}
Purpose: To investigate dynamically the X-ray appearance of cervical degenerative disease induced by unbalanced dynamic and static forces in rats.

Methods: A total of 60 Sprague Dawley rats were randomized into test $(n=45)$ and control $(n=15)$ groups, which were randomly subdivided into the one-, three- and six-month postoperative groups. The test group included 10,15 and 20 rats at the respective corresponding post-operative stage and the control group included five rats at each time-point. By excising cervicodorsal muscles, interspinous ligaments and supraspinous ligament of rats in the test group, the balance of dynamic and static forces on cervical vertebrae was disrupted to establish a rat model of cervical degeneration. Spinal X-ray images were acquired, and intervertebral disc space and intervertebral foramen size were measured at one, three and six months post-operation. The results were analyzed and compared among groups.

Results: Cervical dynamic and static imbalance accelerated the appearance of cervical degenerative disease on X-ray.

Conclusion: Cervical degenerative disease may be induced by unbalanced dynamic and static forces in rats.

Key words: Cervical Vertebrae. X-Rays. Rats.
\end{abstract}




\section{Introduction}

Cervical spondylosis is a common and severe degenerative disease, which seriously affects human health and quality of life. However, the specific pathogenesis remains elusive and may result from multiple factors, including degeneration, trauma, strain, inflammation and congenital malformation, among which cervical degeneration is regarded as an important risk factor for cervical spondylosis ${ }^{1-5}$. According to two-column and three-column spine concepts, respectively elaborated by Holdsworth et al. ${ }^{6}$ and Denis et al. ${ }^{7}$, mechanical instability of the cervical spine is an important factor that accelerates cervical degenerative processes. According to current theories, cervical stability is maintained by two factors: one is an endogenous static equilibrium, consisting of vertebrae, adnexa, intervertebral disc and attached ligaments; the other is an exogenous dynamic equilibrium, regulated and controlled by cervical muscles. Damage to any part is likely to cause cervical instability. Miyamoto et al. ${ }^{8}$ have demonstrated that cervical static instability promotes cervical disc degeneration. Cervical dynamic and static imbalance accelerating cervical degeneration is also confirmed by changes in disc morphology, the activity of associated inflammatory factors (prostaglandin E2; 6-ketoprostaglandin $\mathrm{F} 1$ alpha) and collagenase [matrix metalloproteinase-1 (MMP-1)] levels after establishment of cervical dynamic and static imbalance in rats ${ }^{9,10}$. It was therefore deduced that cervical degenerative disease may be induced by unbalanced dynamic and static forces. Imaging, as a reliable clinical method to study cervical degeneration, however, has not been employed in current research. Therefore, the present study established rat model of cervical dynamic and static imbalance by excising muscles and parts of ligaments in the posterior cervical spine, and observed the X-ray appearance of cervical degenerative disease induced by unbalanced dynamic and static forces in rats.

\section{Methods}

The animal use protocol was reviewed and approved by the Institutional Animal Care and Use Committee (IACUC) of Nanjing Medical University (Nanjing, China).

The present study was performed in strict accordance with the recommendations in the Guide for the Care and Use of Laboratory Animals of the National Institutes of Health.

A total of 60 adult and healthy male Sprague Dawley (SD) rats (age, 6-week-old; weight, 220-250 g; provided by Shanghai Laboratory Animal Center (Shanghai, China) were randomized into test $(n=45)$ and control $(n=15)$ groups, which were subdivided into one-month, three-month and six-month postoperation groups. The test group included 10, 15 and 20 rats at corresponding post-operative stages and the control group had five rats at each time-point. The 2 groups of rats $(n=45$ in the test groups and $n=15$ in the control group) at corresponding post-operative stages were subjected to $x$-ray analysis and compared each other at 1, 3 and 6 months post-operation, respectively.

\section{Model establishment}

Rats in the test group were solidfood fasted for $12 \mathrm{~h}$ prior to the experiment, anesthetized with $10 \%$ chloral hydrate 10.3 $\mathrm{ml} / 100 \mathrm{~g}$; provided by Sinopharm Chemical Reagent Co., Ltd., Shanghai, China) by intraperitoneal injection and fixed on the operating table in the prone position with a 50-ml falcon tube under the neck. The rat was shaved on the nape of the neck and disinfected, following which a $2-2.5 \mathrm{~cm}$ longitudinal incision was made at the midline to perforate the skin and subcutaneous tissue. Every muscle 
layer was fully separated. Superficial muscles, platysma muscle, trapezius and rhomboideus, and deeper muscles, splenius cervicis muscle, longissimus capitis et atlantis, longissimus cervicis, hiocostalis cervicis and semispinalis capitis were transected successively, and 1.5 $\mathrm{cm}$ of those muscles were resected to avoid coalescence. At last, supraspinous ligament and interspinous ligaments from $\mathrm{C} 2$ to $\mathrm{C} 7$ were cut off prior to suturing skin layers successively, without removing the sutures, which came off naturally. The preparation prior to surgery and anesthesia for rats in the pseudo-surgery (control) group was the same as that in the test group. The skin incision of rats in the control group was sutured without resecting or cutting any muscle or ligament. Each rat was fed a standard diet and ad libitum access to food and water in individual cages under normal conditions: Temperature $23-25^{\circ} \mathrm{C}$; relative humidity $40-70 \%$ and a $12-\mathrm{h}$ light/dark cycle with intramuscular injection of 50.000 units penicillin sodium to prevent infection after surgery.

\section{Index assessment}

After model establishment, anterioposterior and lateral X-rays of rat cervical spines were taken at 1,3 and 6 months after surgery by fixing rats in the same position after intraperitoneal anesthesia with $10 \%$ chloral hydrate $(3 \mathrm{ml} / \mathrm{kg}$, provided by Sinopharm Chemical Reagent Co., Ltd., Shanghai, China; catalogue no. 20110401). Anterior, middle and posterior intervertebral space and intervertebral foramen diameters were measured on anterioposterior and lateral images using Photoshop CS2 Version 9.0 (Adobe, San Jose, CA, USA), respectively. Images were captured using the same molybdenum target X-ray machine (model no. 52420658; DirectView Vita CR, CareStream Health, Rochester, NY, USA) under the same conditions (working potential, $220 \mathrm{~V}$; current, 15A).

\section{Statistical analysis}

Values are expressed as the mean \pm standard deviation. Statistical analysis were performed with GraphPad Prism, (version 6; GraphPad Inc., La Jolla, CA, USA). F-test was used to assess the equality of variances. If variances were equal, Students t-test was employed to compare mean values among groups. The Rank-sum test was performed if data were not normally distributed or variances were not equal. $\mathrm{P}<0.05$ was considered to indicate a statistically significant difference.

\section{- Results}

\section{General observation}

A total of 45 SD rats in the test group underwent surgery without any perioperative mortality and subsequent to surgery, characteristics of head bobbing, twisting and shaking were observed, which disappeared within approximately one week. Seven days after surgery, five rats died and were dissected, revealing cervical infection and intestinal tympaniteses. No further mortalities occurred at one, three and six months post-operation.

\section{Cervical spine $X$-rays}

At one month after surgery, no obvious differences in intervertebral space and intervertebral foramen diameters between the test and control groups were observed on X-ray (Figure 1). At three and six months post surgery, $\mathrm{X}$-rays of rat cervical spines in the test group showed loss of cervical lordosis or cervical retroflection, narrowing of intervertebral foramen and reduced intervertebral disc space compared with those in the control group (Figures 2 and 3). 

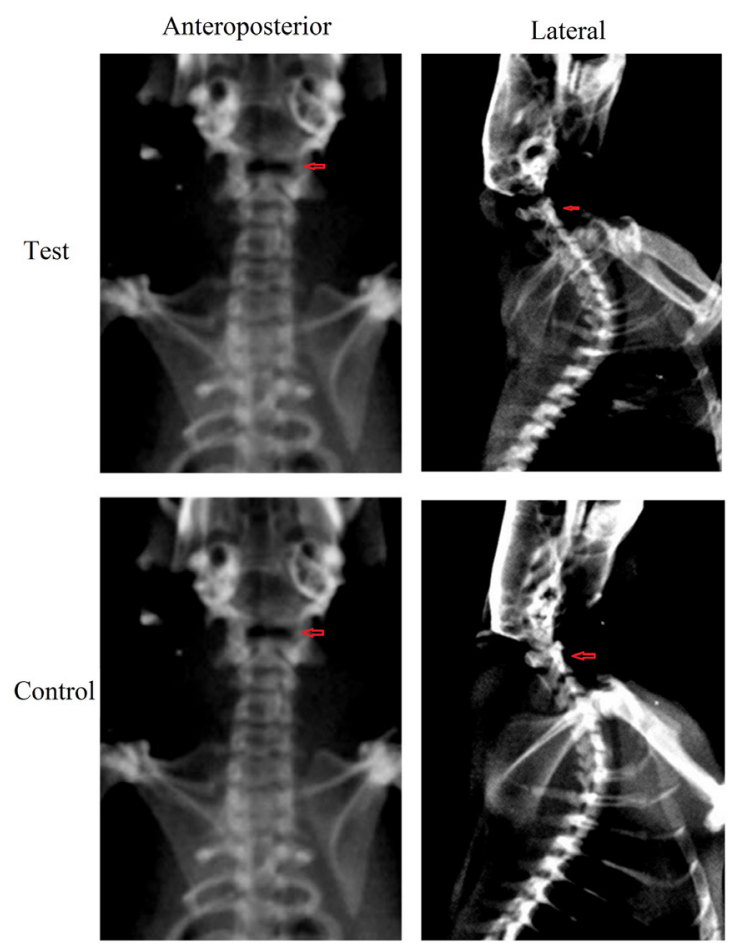

Figure 1 - Representative anteroposterior and lateral spine X-ray of rats in the test and control groups at one month post surgery.
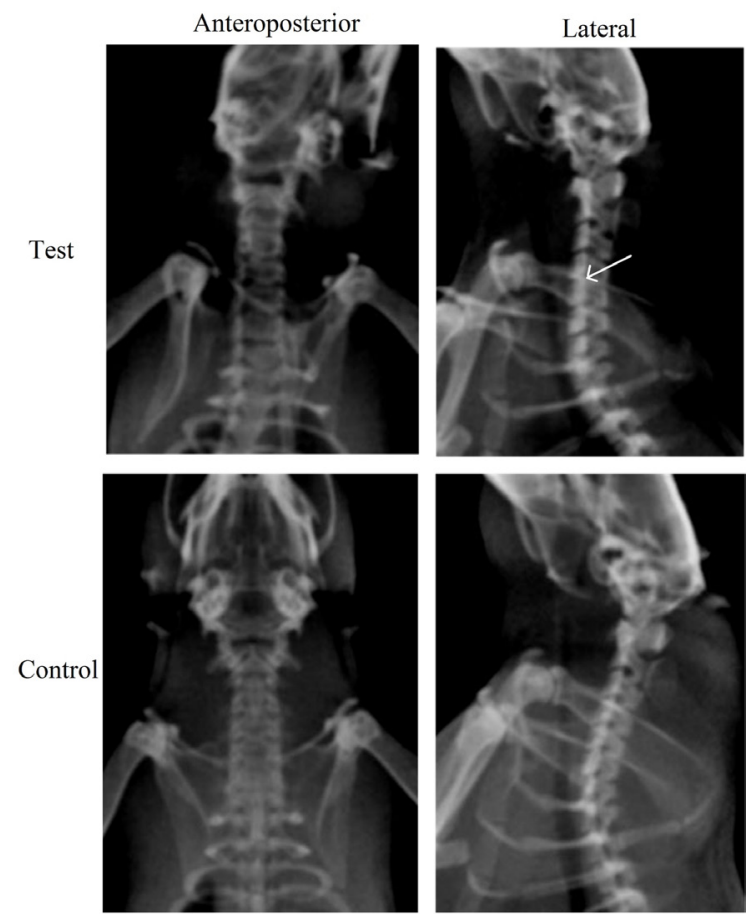

Figure 2 - Representative anteroposterior and lateral spine X-ray of rats in the test and control groups at three months post surgery. Cervical degeneration in the test group is indicated by an arrow.
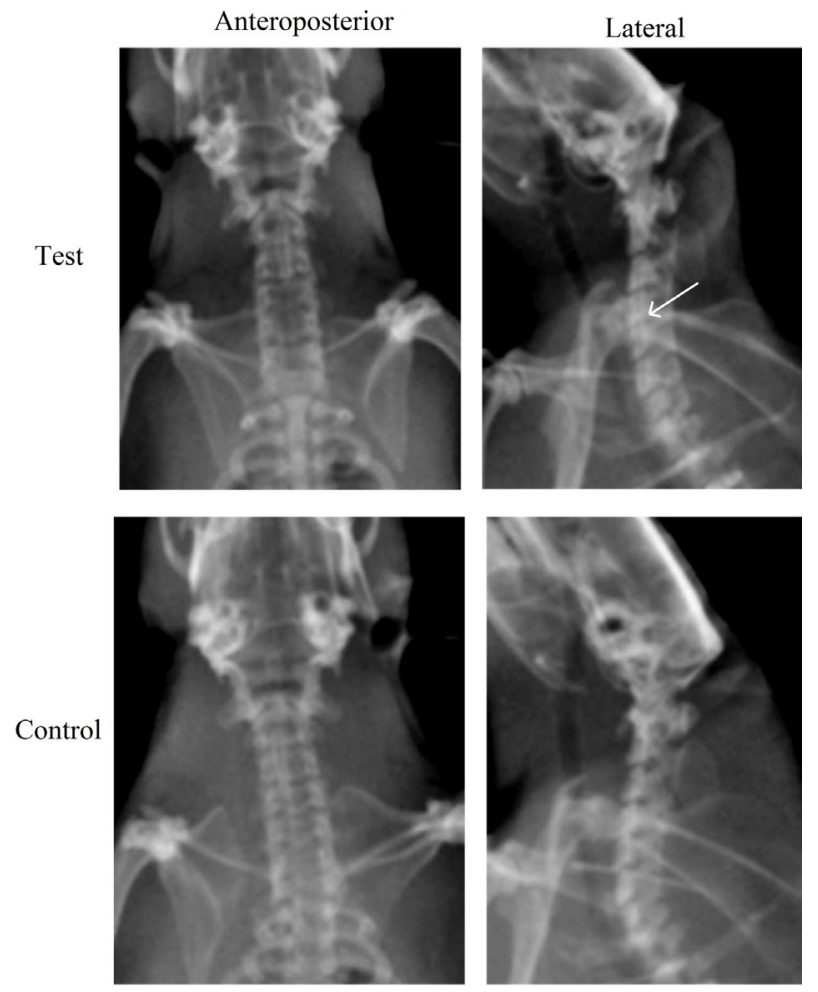

Figure 3 - Representative anteroposterior and lateral spine X-ray of rats in the test and control groups at six months post surgery. Cervical degeneration in the test group is indicated by an arrow.

\section{Outcome of statistical analysis}

The results of intervertebral space measurements in anteroposterior and lateral $\mathrm{X}$-rays as well as the intervertebral foramen diameter of rat cervical spines are shown in Tables 1-4, respectively. Compared with those in the control group, intervertebral spaces and intervertebral foramen diameter of rats in the test group were similar at one month post-surgery $(P>0.05)$. However, the C2-3, C3-4, C4-5 and C5-6 intervertebral spaces obtained in anterioposterior position were significantly reduced 6 months postoperation compared with those in the control group $(\mathrm{P}<0.05$ or $\mathrm{P}<0.01$; Table 1$)$. The $\mathrm{C} 4-5$ anterior and posterior intervertebral space were significantly decreased at three postoperative months (lateral $\mathrm{X}$-ray; $\mathrm{P}<0.05$; in Table 3), and the C2-3 (Table 2) middle and 
posterior, C3-4 (Table 2), C4-5 (Table 3) and C5-6 (Table 3) posterior as well as the C6-7 (Table 3) anterior and middle intervertebral spaces were significantly reduced at six postoperative months compared with those in the control group (lateral $\mathrm{X}$-ray; $\mathrm{P}<0.05, \mathrm{P}<0.01$ or $\mathrm{P}<0.001)$. Furthermore, at six post-operative months, the C4-5, C5-6 and C6-7 intervertebral foramens were significantly narrowed compared with those in the control group $(P<0.05$ and $\mathrm{P}<0.01$, respectively, Table 4).

In the test groups, the intervertebral space and intervertebral foramen diameter of rats were not statistically different between 1 and 3 months post-operation, while 6-month post-operative C2-3, C5-6 from anteroposterior $X$-ray were evidently decreased compared with the corresponding parameters at one month $(P<0.05$; Table 1). Six-month post-operation C4-5, C5-6 and C6-7 intervertebral foramen were significantly narrowed compared with the corresponding 1-month post-operative parameters $(P<0.05$; Table 4$)$, while there was no difference in intervertebral space and intervertebral foramen diameter between 3 and 6 months post-operation.

Table 1 - Measurement results of various intervertebral disc spaces ( $\mathrm{mm}$ ) obtained from X-ray images in anterioposterior position.

\begin{tabular}{llllll}
\hline $\begin{array}{l}\text { Group/time post-surgery } \\
\text { (months) }\end{array}$ & $\mathbf{C 2 - 3}$ & $\mathbf{C 3 - 4}$ & $\mathbf{C 4 - 5}$ & $\mathbf{C 5}-6$ & C6-7 \\
\hline $\begin{array}{l}\text { Test } \\
1\end{array}$ & $0.12 \pm 0.01$ & $0.12 \pm 0.01$ & $0.12 \pm 0.01$ & $0.13 \pm 0.05$ & $0.10 \pm 0.02$ \\
3 & $0.10 \pm 0.01$ & $0.11 \pm 0.01$ & $0.11 \pm 0.01$ & $0.11 \pm 0.02$ & $0.11 \pm 0.01$ \\
6 & $0.09 \pm 0.04^{\mathrm{a}, \mathrm{c}}$ & $0.12 \pm 0.05^{\mathrm{a}}$ & $0.12 \pm 0.02^{\mathrm{a}}$ & $0.10 \pm 0.05^{\mathrm{b}, \mathrm{c}}$ & $0.12 \pm 0.03$ \\
Control & & & & & \\
1 & $0.11 \pm 0.01$ & $0.10 \pm 0.01$ & $0.11 \pm 0.01$ & $0.12 \pm 0.01$ & $0.09 \pm 0.01$ \\
3 & $0.11 \pm 0.02$ & $0.12 \pm 0.02$ & $0.12 \pm 0.01$ & $0.11 \pm 0.01$ & $0.12 \pm 0.02$ \\
6 & $0.13 \pm 0.03$ & $0.15 \pm 0.02$ & $0.14 \pm 0.02$ & $0.17 \pm 0.05$ & $0.12 \pm 0.01$ \\
\hline
\end{tabular}

Values are expressed as the mean \pm standard deviation. ${ }^{\mathrm{a}} \mathrm{P}<0.05,{ }^{\mathrm{b}} \mathrm{P}<0.01$ vs. control group; $\mathrm{c}^{\mathrm{a} 2} \mathrm{P}<0.05$ vs. 1 -month post-operative parameters in test group.

Table 2 - Measurement results of various intervertebral disc spaces $(\mathrm{mm})$ obtained from X-ray images in lateral position for C2-3 and C3-4.

\begin{tabular}{|c|c|c|c|c|c|c|}
\hline $\begin{array}{l}\text { Group/time } \\
\text { post-surgery } \\
\text { (months) }\end{array}$ & $\begin{array}{l}\text { C2-3 } \\
\text { Anterior }\end{array}$ & Middle & Posterior & $\begin{array}{l}\text { C3-4 } \\
\text { Anterior }\end{array}$ & Middle & Posterior \\
\hline \multicolumn{7}{|l|}{ Test } \\
\hline 1 & $0.14 \pm 0.01$ & $0.13 \pm 0.01$ & $0.12 \pm 0.02$ & $0.13 \pm 0.01$ & $0.12 \pm 0.01$ & $0.12 \pm 0.01$ \\
\hline 3 & $0.11 \pm 0.02$ & $0.11 \pm 0.02$ & $0.09 \pm 0.02$ & $0.11 \pm 0.01$ & $0.10 \pm 0.02$ & $0.09 \pm 0.02$ \\
\hline 6 & $0.14 \pm 0.02$ & $0.10 \pm 0.01^{c}$ & $0.10 \pm 0.02^{b}$ & $0.13 \pm 0.03$ & $0.11 \pm 0.01$ & $0.10 \pm 0.02^{a}$ \\
\hline \multicolumn{7}{|l|}{ Control } \\
\hline 1 & $0.13 \pm 0.01$ & $0.12 \pm 0.01$ & $0.11 \pm 0.01$ & $0.13 \pm 0.01$ & $0.12 \pm 0.00$ & $0.11 \pm 0.01$ \\
\hline 3 & $0.12 \pm 0.01$ & $0.12 \pm 0.02$ & $0.10 \pm 0.02$ & $0.11 \pm 0.02$ & $0.11 \pm 0.01$ & $0.10 \pm 0.01$ \\
\hline 6 & $0.17 \pm 0.04$ & $0.15 \pm 0.01$ & $0.14 \pm 0.01$ & $0.14 \pm 0.03$ & $0.12 \pm 0.01$ & $0.12 \pm 0.01$ \\
\hline
\end{tabular}

Values are expressed as the mean \pm standard deviation. ${ }^{a} \mathrm{P}<0.05,{ }^{\mathrm{b}} \mathrm{P}<0.01,{ }^{\mathrm{c}} \mathrm{P}<0.001$ vs. control group. 
Table 3 - Measurement results of various intervertebral disc spaces ( $\mathrm{mm}$ ) obtained from X-ray images in lateral position for C4-5, C5-6 and C6-7.

\begin{tabular}{|c|c|c|c|c|c|c|c|c|c|}
\hline $\begin{array}{l}\text { Group/ } \\
\text { time } \\
\text { post- } \\
\text { surgery } \\
\text { (months) }\end{array}$ & Anterior & Middle & Posterior & Anterior & Middle & Posterior & Anterior & Middle & Posterior \\
\hline \multicolumn{10}{|l|}{ Test } \\
\hline 1 & $0.12 \pm 0.00$ & $0.12 \pm 0.01$ & $0.11 \pm 0.02$ & $0.12 \pm 0.01$ & $0.11 \pm 0.01$ & $0.10 \pm 0.02$ & $0.13 \pm 0.01$ & $0.12 \pm 0.01$ & $0.11 \pm 0.01$ \\
\hline 3 & $0.09 \pm 0.02^{\mathrm{a}}$ & $0.11 \pm 0.01$ & $0.10 \pm 0.02$ & $0.11 \pm 0.2$ & $0.10 \pm 0.02$ & $0.09 \pm 0.02$ & $0.11 \pm 0.01$ & $0.10 \pm 0.01^{a}$ & $0.09 \pm 0.01$ \\
\hline 6 & $0.10 \pm 0.02$ & $0.12 \pm 0.03^{\mathrm{a}}$ & $0.09 \pm 0.02^{c}$ & $0.14 \pm 0.01^{\mathrm{a}}$ & $0.11 \pm 0.01^{c}$ & $0.10 \pm 0.02^{c}$ & $0.14 \pm 0.01^{b}$ & $0.13 \pm 0.01^{c}$ & $0.12 \pm 0.02$ \\
\hline \multicolumn{10}{|l|}{ Control } \\
\hline 1 & $0.11 \pm 0.00$ & $0.10 \pm 0.00$ & $0.13 \pm 0.01$ & $0.13 \pm 0.01$ & $0.11 \pm 0.00$ & $0.11 \pm 0.00$ & $0.12 \pm 0.01$ & $0.12 \pm 0.01$ & $0.11 \pm 0.02$ \\
\hline 3 & $0.12 \pm 0.02$ & $0.10 \pm 0.01$ & $0.12 \pm 0.01$ & $0.12 \pm 0.01$ & $0.11 \pm 0.02$ & $0.09 \pm 0.02$ & $0.12 \pm 0.02$ & $0.11 \pm 0.01$ & $0.10 \pm 0.02$ \\
\hline 6 & $0.12 \pm 0.01$ & $0.14 \pm 0.03$ & $0.12 \pm 0.03$ & $0.16 \pm 0.03$ & $0.14 \pm 0.04$ & $0.14 \pm 0.02$ & $0.19 \pm 0.04$ & $0.15 \pm 0.01$ & $0.13 \pm 0.01$ \\
\hline
\end{tabular}

Values are expressed as the mean \pm standard deviation. ${ }^{\mathrm{a}} \mathrm{P}<0.05,{ }^{\mathrm{b}} \mathrm{P}<0.001,{ }^{\mathrm{c}} \mathrm{P}<0.01$ vs. control group.

Table 4 - Measurement results of the intervertebral foramen diameter in various intervertebral disk spaces $(\mathrm{mm})$ obtained from X-ray images in lateral position.

\begin{tabular}{llllll}
\hline $\begin{array}{l}\text { Group/time post- } \\
\text { surgery (months) }\end{array}$ & C2-3 & C3-4 & C4-5 & C5-6 & C6-7 \\
\hline $\begin{array}{lllll}\text { Test } \\
1\end{array}$ & $0.30 \pm 0.03$ & $0.24 \pm 0.03$ & $0.22 \pm 0.02$ & $0.24 \pm 0.03$ & $0.24 \pm 0.02$ \\
3 & $0.26 \pm 0.03$ & $0.21 \pm 0.03$ & $0.20 \pm 0.03$ & $0.20 \pm 0.04$ & $0.20 \pm 0.04$ \\
6 & $0.29 \pm 0.04$ & $0.22 \pm 0.04$ & $0.19 \pm 0.03^{\mathrm{a}, \mathrm{c}}$ & $0.19 \pm 0.02^{\mathrm{b}, \mathrm{c}}$ & $0.17 \pm 0.08^{\mathrm{b}, \mathrm{d}}$ \\
Control & & & & & \\
1 & $0.28 \pm 0.02$ & $0.23 \pm 0.02$ & $0.22 \pm 0.05$ & $0.24 \pm 0.03$ & $0.22 \pm 0.02$ \\
3 & $0.27 \pm 0.01$ & $0.25 \pm 0.02$ & $0.21 \pm 0.02$ & $0.22 \pm 0.02$ & $0.20 \pm 0.03$ \\
6 & $0.33 \pm 0.02$ & $0.26 \pm 0.05$ & $0.25 \pm 0.03$ & $0.25 \pm 0.02$ & $0.25 \pm 0.04$ \\
\hline
\end{tabular}

Values are expressed as the mean \pm standard deviation. ${ }^{\mathrm{a}} \mathrm{P}<0.05,{ }^{\mathrm{b}} \mathrm{P}<0.01$ vs. control group, ${ }^{\mathrm{c}} \mathrm{P}<0.05,{ }^{\mathrm{d}} \mathrm{P}<0.01$ vs. 1 -month post-operative parameters in test group.

\section{Discussion}

The mechanical system that maintains cervical stability includes a static and a dynamic system, which serve as the basis and prerequisite of spinal integrity. In the neutral position, the normal physiological movement and stability of the neck are achieved by adjusting the strain of surrounding muscles to generate a dynamic balance on the basis of the static balance ${ }^{11}$. During the development of cervical degenerative disease, unbalanced static and dynamic systems of cervical vertebrae have a synergistic effect on each other. A dynamic imbalance tends to occur at the early stage of cervical degenerative disease. First, exogenous pathological factors directly or indirectly influence the cervical dynamic system, i.e., cervical muscles are weakened due to long-term and persistent 
strain and irritation. The thereby generated dynamic imbalance results in an out-of-sync static system that comprises cervical vertebral bodies, ligaments and intervertebral discs, followed by a biomechanical imbalance of the cervical spine to cause cervical instability and cervical intervertebral disc degeneration, which may lead to annulus fibrosus corruption, nucleus pulposus extrusion, vertebral body collapse as well as intervertebral disc space and intervertebral foramen stenosis. Consequently, complex symptoms occur due to mechanical compression of the cervical nerve root, blood vessels and spinal cord by intervertebral discs and osteophyte. Establishment of a cervical dynamic imbalance in rats has been demonstrated to induce changes in the direction and level of pressure upon the articular surface of the cervical spine, followed by degenerative changes of articular cartilage and capsule ${ }^{12,13}$. Kawaguchi et $a .^{14}$ reported that axial symptoms following cervical laminoplasty included post-operative pain, soreness, weakness, spasm and stiffness from the nuchal to the scapular region. Certain studies consider axial symptoms as the causal effect of intraoperative muscle and ligament injuries. Kawaguchi et al. ${ }^{15}$ found that axial symptoms were more common in patients who underwent anterior cervical decompression and fusion surgery due to long-term postoperative wearing of a cervical collar to limit motion, resulting in atrophy of posterior cervical muscles and further decreasing the range of motion of the cervical spine. Fujibayashi et al. ${ }^{16}$ explored the cause of axial symptoms in patients with cervical spondylotic myelopathy who underwent cervical laminoplasty and revealed the close association between axial symptoms and the recovery of (dynamic balance-associated) cervical muscles. Thus, maintenance of a dynamic balance involving cervical muscles and ligaments has important implications for not only reducing the incidence of cervical spondylosis, but also influencing the therapeutic effect of surgery and promoting post-operative recovery ${ }^{14-17}$.

Cervical instability models may be utilized for investigating the cause and pathogenesis of cervical spondylosis. In the present study, a rat model of unbalanced dynamic and static forces on the cervix was established by dissecting the posterior cervical muscles, supraspinous and interspinous ligaments to simulate muscle strain and decrease of myodynamia in humans.

Imaging (X-ray, computed tomography, magnetic resonance imaging and myelography) as a convenient, quick and practical method, has been widely applied in the clinical diagnosis of cervical spondylosis, while X-ray is most commonly used. The present study assessed the changes in intervertebral space and intervertebral foramen diameter on X-ray images of the cervical spine to objectively reflect the degree of cervical degeneration. The results revealed that at three and six months post surgery, the X-ray appearance of the cervix in the test group was significantly different from that in the control group, suggesting cervical degeneration. The aforementioned results indicated that the unbalance of dynamic and static forces on cervical vertebrae may be an important factor that leads to acceleration of cervical degeneration in rats, which is consistent with the initial hypothesis. However, due to the difference in the physiological properties of cervical spines between rats and humans, a rat model of cervical dynamic and static imbalance cannot resemble cervical degenerative processes in humans. Therefore, further research on the pathogenesis of cervical spondylosis requires abundant models that more closely resemble the human cervical spine.

Studies have found that bone changes induced by cervical degenerative disease are not the only cause of cervical spondylosis 
symptoms. Certain patients with severe symptoms showed unobvious degenerative changes on cervical spine X-ray. A number of studies have demonstrated that the combination of cervical spine degeneration and changes in nucleus pulposus and its extracellular matrix are involved in the pathology of cervical spondylosis ${ }^{18-21}$. Studies establishing a dynamic non-equilibrium involving the cervical spine in rats found that the annulus fibrosus progressively degenerated and ruptured, and the nucleus pulposus gradually shrank and disappeared entirely over time ${ }^{10,22}$. Kääpä et al. ${ }^{23}$ reported markedly increased activity of intervertebral collagenase and serinase and distinctly decreased levels of proteoglycan. Wang et al. ${ }^{9}$ demonstrated significant changes in disc morphology, the activity of associated inflammatory factors (prostaglandin E2, 6-keto-prostaglandin F1 alpha) and collagenase (MMP-1) levels during cervical degenerative processes induced by cervical dynamic and static imbalance in rats. Changes in various inflammatory factors have also been identified during processes of intervertebral disc degeneration ${ }^{24-28}$. It was therefore speculated that cervical dynamic and static imbalances may cause an X-ray appearance of cervical degeneration, accompanied by changes in intervertebral disc cells and extracellular matrix, which provided direction for further study. In an adjunct study by our group, the inflammatory factors in serum and intervertebral discs in rats prior to and after surgery were assessed to determine the most important changes and the corresponding mechanisms.

The results of the present study suggested that cervical dynamic and static imbalance may accelerate the cervical degenerative appearance, specifically in C4-5 and C5-6 intervertebral spaces on X-ray. Therefore, the current study concludes that cervical dynamic and static imbalance may simulate the degenerative process of cervical spine in certain patients. However, given the complexity of human disc degeneration no animal model is able to perfectly mimic the entire pathophysiological process. Therefore, further research and improved animal models are required to confirm the conclusion of the present study.

\section{References}

1. Gruber HE, Hanley EN Jr. Analysis of aging and degeneration of the human intervertebral disc comparison of surgical specimens with normal controls. Spine (Phila Pa 1976). 1998 Apr 1;23(7):751-7. PMID: 9563104.

2. Yoshimura $S$, Shimosato $A$, Imanami $M$, Hatanaka T, Yasunaga S. Awake intubation using Pentax-airway scope combined with surface airway anesthesia in the cases of two obese patients with cervical spondylosis and the author himself. Masui. 2012 Jul;61(7):738-41. PMID: 22860303.

3. Liang ZH, Di Z, Jiang S, Xu SJ, Zhu XP, Fu WB, Lu AP. The optimized acupuncture treatment for neck pain caused by cervical spondylosis: a study protocol of a multicentre randomized controlled trial. Trials. 2012 Jul 9;13:107. PMID: 22776567.

4. McDonnell M, Lucas P. Cervical spondylosis, stenosis, and rheumatoid arthritis. Med Health R I. 2012 Apr;95(4):105-9. PMID: 22712188.

5. Boontangjai C, Keereratnikom T, Tangtrakulwanich B. Operative results of laminoplasty in multilevel cervical spondylosis with myelopathy: a comparison of two surgical techniques. J Med Assoc Thai. 2012 Mar;95(3):378-82. PMID: 22550836.

6. Holdsworth F. Fractures, dislocations, and fracture-dislocations of the spine. J Bone Joint Surg Am. 1970 Dec;52(8):1534-51. PMID: 5483077.

7. Denis F. The three column spine and its significance in the classification of acute thoracolumbar spinal injuries. Spine (Phila Pa 1976). 1983 Nov-Dec;8(8):817-31. PMID: 6670016.

8. Miyamoto S, Yonenobu K, Ono K. Experimental cervical spondylosis in the mouse. Spine (Phila Pa 1976). 1991 Oct;16(10 Suppl):S495-500. PMID: 1801260. 
9. Wang YJ, Shi Q, Lu WW, Cheung KC, Darowish M, Li TF, Dong YF, Zhou CJ, Zhou Q, Hu ZJ, Liu M, Bian Q, Li CG, Luk KD, Leong JC. Cervical intervertebral disc degeneration induced by unbalanced dynamic and static forces: a novel in vivo rat model. Spine (Phila Pa 1976). 2006 Jun 15;31(14):1532-8. PMID: 16778684.

10.An HS, Takegami K, Kamada H, Nguyen CM, Thonar EJ, Singh K, Andersson GB, Masuda K. Intradiscal administration of osteogenic protein-1 increases intervertebral disc height and proteoglycan content in the nucleus pulposus in normal adolescent rabbits. Spine (Phila Pa 1976). 2005 Jan 1;30(1):25-31; discussion 31-2. PMID: 15626976.

11.Shedid D, Benzel EC. Cervical spondylosis anatomy: pathophysiology and biomechanics. Neurosurgery. 2007 Jan;60(1 Supp1 1):S7-13. PMID: 17204889.

12.Yang B, Li H, Zhang T, He X, Xu S. The incidence of adjacent segment degeneration after cervical disc arthroplasty (CDA): a meta analysis of randomized controlled trials. PLoS One. 2012;7(4):e35032. PMID: 22558112.

13.Ferrara LA. The biomechanics of cervical spondylosis.AdvOrthop.2012;2012:493605. PMID: 22400120.

14.Kawaguchi $Y$, Matsui $H$, Ishihara $H$, Gejo $\mathrm{R}$, Yoshino O. Axial symptoms after enbloc cervical laminoplasty. J Spinal Disord. 1999 Oct;12(5):392-5. PMID: 10549702.

15. Kawaguchi Y, Nagami S, Nakano M, Yasuda T, Seki S, Hori T, Kimura T. Relationship between postoperative axial symptoms and the rotational angle of the cervical spine after 1aminoplasty. Eur J Orthop Surg Traumatol. 2013 Jul;23 Suppl 1:S53-8. PMID: 23563624.

16.Fujibayashi S, Neo M, Yoshida M, Miyata M, Takemoto M, Nakamura T. Neck muscle strength before and after cervical laminoplasty: relation to axial symptoms. J Spinal Disord Tech. 2010 May;23(3):197202. PMID: 20072032.

17. Wharton SB, Chan KK, Pickard JD, Anderson JR. Paravertebral muscles in disease of the cervical spine. J Neurol Neurosurg Psychiatry. 1996 Nov;61(5):461-5. PMID: 8937338.

18.Jeong JH, Lee JH, Jin ES, Min JK, Jeon SR, Choi
$\mathrm{KH}$. Regeneration of intervertebral discs in a rat disc degeneration model by implanted adipose-tissue derived stromal cells. Acta Neurochir (Wien). 2010 Oct;152(10):17717. PMID: 20571835.

19.Gaetani P, Torre ML, Klinger M, Faustini M, Crovato F, Bucco M, Marazzi M, Chlapanidas T, Levi D, Tancioni F, Vigo D, Rodriguez y Baena R. Adipose-derived stem cell therapy for intervertebral disc regeneration: an in vitro reconstructed tissue in alginate capsules. Tissue Eng Part A. 2008 Aug;14(8):1415-23. PMID: 18593270.

20.Mwale F, Roughley P, Antoniou J. Distinction between the extracellular matrix of the nucleus pulposus and hyaline cartilage: a requisite for tissue engineering of intervertebral disc. Eur Cell Mater. 2004 Dec 15;8:58-63; discussion 63-4. PMID: 15602703.

21.Sobajima S, Shimer AL, Chadderdon RC, Kompel JF, Kim JS, Gilbertson LG, Kang JD. Quantitative analysis of gene expression in a rabbit model of intervertebral disc degeneration by real-time polymerase chain reaction. Spine J. 2005 Jan-Feb;5(1):14-23. PMID: 15653081.

22. Anderson DG, Izzo MW, Hall DJ, Vaccaro AR, Hilibrand A, Arnold W, Tuan RS, Albert TJ. Comparative gene expression profiling of normal and degenerative discs: analysis of a rabbit annular laceration model. Spine (Phila Pa 1976). 2002 Jun 15;27(12):1291-6. PMID: 12065976.

23. Kääpä E, Han X, Holm S, Peltonen J, Takala T, Vanharanta $\mathrm{H}$. Collage synthesis and type I, III, IV and VI coUage in animal model of disc degeneration. Spine (Phila Pa 1976). 1995 Jan 1;20(1):59-66; discussion 66-7. PMID: 7709281.

24. Blanquer SB, Grijpma DW, Poot AA. Delivery systems for the treatment of degenerated intervertebral discs. Adv Drug Deliv Rev. 2015 Apr;84:172-87. PMID: 25451138.

25.Wang SZ, Rui YF, Tan Q, Wang C. Enhancing intervertebral disc repair and regeneration through biology: platelet-rich plasma as an alternative strategy. Arthritis Res Ther. 2013;15(5):220. PMID: 24165687.

26. Risbud MV, Shapiro IM. Role of cytokines in intervertebral disc degeneration: pain and disc content. Nat Rev Rheumatol. 2014 Jan;10(1):44-56. PMID: 24166242. 
27.Phillips KL, Cullen K, Chiverton N, Michael $A L$, Cole AA, Breakwell LM, Haddock $\mathrm{G}$, Bunning RA, Cross AK, Le Maitre CL. Potential roles of cytokines and chemokines in human intervertebral disc degeneration: interleukin-1 is a master regulator of catabolic processes. Osteoarthritis Cartilage. 2015 Jul;23(7):1165-77. PMID: 25748081.
28.Ozkanli S, Kaner T, Efendioglu M, Basaran $R$, Senol $M$, Zemheri $E$, Gezen AF. The relation of matrix metalloproteinase 1,2 , 3 expressions with clinical and radiological findings in primary and recurrent lumbar disc herniations. Turk Neurosurg. 2015;25(1):111-6. PMID: 25640554.

\section{Correspondence:}

Luming Nong,

Department of Orthopedics

Changzhou Second People's Hospital Affiliated

to Nanjing Medical University

29 Xinglong Xiang, Zhonglou

Changzhou 213003, Jiangsu, P.R. China

lumingnongdc@126.com

Received: May 12, 2017

Review: July 14, 2017

Accepted: Aug 18, 2017
Conflict of interest: none

Financial source: Changzhou High-level Medical Talents Training Project (grant no. 2016CZBJ029)
${ }^{1}$ Research performed at Laboratory of Changzhou, Second People's Hospital Affiliated to Nanjing Medical University, Jiangsu, P.R. China. 